\title{
Pneumologia
}

\section{EVALI - why was it mandatory or necessary to study a new disease?}

Florin Mihălțan*

"Marius Nasta" Institute of Pneumophtysiology, Bucharest, Romania

Abstract

English:

E-cigarette has a long history. From 1965 until now, we accepted the promotional campaigns of the tobacco industry and now a new epidemic disease EVALI is generated with an explosion of deaths and pulmonary lesions. We need now to learn more about the algorithm of diagnosis and treatment. This article is updating for 2019 the guideline of diagnosis and treatment of this new disease.

Keywords

\section{EVALI - de ce este absolut necesar să studiem o nouă boală?}

Rezumat

\section{Romanian:}

Țigara electronică are o istorie lungă. Din 1965 și până acum am acceptat campaniile promoționale ale industriei tutunului și acum o nouă boală epidemică, EVALI, a fost generată, cu o explozie de decese și leziuni pulmonare. Acum trebuie să învătăm mai multe despre algoritmul de diagnostic și tratament al acesteia. Acest articol actualizează pentru anul 2019 ghidul de diagnostic și tratament al acestei noi boli.

Cuvinte-cheie

țigara electronică • leziune pulmonară asociată țigării electronice și vapingului (EVALI)

\section{Editorial}

Electronic cigarette (e-cigarette) has a long history. Initially discovered by Gilbert (1) in 1965, this non-tobacco cigarette was thought to be a safe and harmless method of smoking by replacing burning tobacco and paper with heated, moist and flavoured air. Hon Lik, a Chinese pharmacist in 2003, invented the first generation of e-cigarette using a piezoelectric element to vapourise the liquid containing nicotine, diluted in a propylene glycol solution (2). In 2007, it was introduced in the US. After the success of e-cigarette sales in Asia, products were sold through the Internet in large quantities. These e-cigarettes conquered the world, and the major transnational tobacco companies developed the business acquiring the small producers of e-cigarette (Lorillard managed to by "Blu", the leading e-cigarette brand in the US; Altria acquired "Green Smoke" and has its own "MarkTen" brand and Reynolds created its own brand "Vuse"). The "smell" of business was everywhere in the world. The British American Tobacco sells "Vype", Imperial Tobacco sells "Ruyan" and Swisher sells 
"E-Swisher". In the US, "Logic" and "NJOY" are now especially the leading e-cigarette companies. This explains why in the US, e-cigarette sales have grown at an annual rate of $115 \%$ in the 2009-2012 period and the global e-cigarette market increased to $\$ 10$ billion by 2017 (3). The first signal concerning the side health effects came soon. Every organ specialist found evidences in the published papers concerning the consequences and lesions induced by e-cigarettes. In 2019, it was something more: a explosion of hospitalised cases and deaths to young consumers of e-cigarettes. The authorities and the medical staff concerned about the growing epidemic evidences linked to e-cigarettes started to react together. We needed 16 years to discover and describe the new disease induced by e-cigarettes, which received finally a name EVALI. The Centers for Disease Control and Prevention (CDC) has issued two advisories very recently - one was on how to evaluate flu-like symptoms in the face of concerns about vaping, and the other was about how the CDC will count and report this new e-cigarette and vaping-associated lung injuries (EVALIs) (4). What is EVALI? EVALI is the name of this new lung disease (covering different types of lesions) generate by e cigarette and vaping. Characteristics of EVALI include respiratory symptoms such as cough, chest pain and shortness of breath, and gastrointestinal symptoms including abdominal pain, nausea, vomiting and diarrhoea. Other symptoms may include fever, chills, weight loss, with direct consequence the death (5). In the US, the country experiencing an unprecedented outbreak of this disease, the specialists found (6) that all the patients used e-cigarettes ( $\geq 85 \%$ of the patients also used the products containing tetrahydrocannabinol (THC), the principal psychoactive component of cannabis). Among 4,631 respondents of a survey (6), 94\% reported using any nicotinecontaining e-cigarette, or vaping, products in the past 3 months, $21 \%$ reported using any THC-containing products and $11 \%$ reported using both THC-containing products and nicotine-containing products (among the sample of respondents aged 18-24 years, the prevalence of THCcontaining products was the highest $-36 \%)$. They compared the EVALI patients aged 18-44 years with a subset of 519 survey respondents aged 18-44 years who reported use of THC-containing e-cigarettes, or vaping, products. They found that EVALI patients had higher odds of reporting exclusive use of THC-containing products (adjusted odds ratio $(\mathrm{aOR})=2.0$, $95 \%$ confidence interval $(\mathrm{Cl})=1.1-3.6)$, frequent use (more than five times per day) of these products (aOR $=3.1,95 \%$ $\mathrm{Cl}=1.6-6.0)$ and obtaining these products from informal sources, such as a dealer, off the street or from a friend $(\mathrm{aOR}=9.2,95 \% \mathrm{Cl}=2.2-39.4)$. First current recommendations were in October 2019 not to use e-cigarette, or vaping, products that contain THC and not to use any e-cigarette, or vaping, products obtained from informal sources (6). This was the first report to analyse e-cigarette, or vaping, product use behaviours associated with an increased risk of EVALI during this outbreak. Another step was to study the potential causes. Analyses of THC-containing product samples by the Food and Drug Administration and state public health laboratories have identified potentially harmful constituents in these products, such as vitamin $\mathrm{E}$ acetate, medium chain triglyceride oil and other lipids $(7,8)$. Vitamin $E$ acetate inhaled might impair lung function $(9,10)$, and it was found in the same time as an additive in e-cigarette and vaping products and as a thickening agent in THC products (11). In the bronchoalveolar lavage (BAL), some authors (12) confirmed the presence of vitamin $E$ acetate. This was the first reported identification of a potential toxicant of concern (vitamin $E$ acetate) in biologic specimens obtained from EVALI patients, without excluding other possible causes, and these findings reinforce the initial CDC's recommendation that people should not use e-cigarette, or vaping, products containing THC, especially those obtained from informal sources such as friends or family, or those from the illicit market, where product ingredients are unknown or can be highly variable (13). Reports came one after the other from the CDC. On 22 October 2019, 49 states, DC and the US Virgin Islands had reported 1,604 cases of EVALI to the CDC, including $34(2.1 \%)$ EVALI-associated deaths in 24 states. Among 1,378 patients with confirmed or probable EVALI reported to the CDC by 15 October 2019, with available data, $964(70 \%)$ were males. Among 867 patients with available data on substances used, $749(86 \%)$ reported any use of THCcontaining products and $552(64 \%)$ reported any use of nicotine-containing products in the 3 months preceding symptom onset; 455 patients (52\%) reported use of both THCcontaining products and nicotine-containing products, 294 (34\%) reported exclusive use of THC-containing products and $97(11 \%)$ reported exclusive use of nicotine-containing products (14). Twenty-one (2\%) patients reported no use of THC- or nicotine-containing products (14). The median age of EVALI patients who survived was 23 years, and the median age of EVALI patients who died was 45 years (14). All the reports had some limits; the most important was that data on substances used in e-cigarette, or vaping, products were selfreported or reported by proxies and might be subject to recall bias as well as social desirability bias because nonmedical marijuana is illegal in many states. Of course also these data might be subject to misclassification of substance use for multiple reasons. On November, another report (15) brought some new data: $5 \%$ of patients were not hospitalised. The hospitalised and non-hospitalised patients had similar demographic and product use characteristics, and influenza vaccination should be considered for all people using e-cigarettes. What seems important for all specialists in this moment is the "Update: Interim Guidance for Health Care Providers for Managing Patients with Suspected E-cigarette, or Vaping, Product Use-Associated Lung Injury - United 
States" published in November 2019 (16). What they recommend is vital as medical knowledge, and every doctor and health provider must follow the same steps. These recommendations are divided into five chapters: 1) initial clinical evaluation, 2) suggested criteria for hospital admission and treatment, 3) patient follow-up, 4) special considerations for groups at high risk and 5) clinical and public health recommendations. History of patients needs to be analysed in detail. We have to ask all patients about respiratory, gastrointestinal and constitutional symptoms (e.g. cough, chest pain, shortness of breath $-95 \%$ of the cases; abdominal pain, nausea, vomiting, diarrhoea $-77 \%$ of the cases; chills, weight loss and fever $-85 \%$ of the cases) who report a history of using e-cigarette, or vaping, products. We have to ask also about recent use of e-cigarette, or vaping, products and types of substances used (e.g. THC, cannabis (oil, dabs), nicotine, modified products or the addition of substances not intended by the manufacturer); we need more information on product source, specific product brand and name, duration and frequency of use, time of last use, product delivery system and method of use (aerosolisation, dabbing or dripping). Physical examination must include assessment of vital signs and pulse oximetry; tachycardia (55\%), tachypnea (45\%) and hypoxemia have been commonly reported among cases $(17,18)$. Another recommendation is to assess vital signs and oxygen saturation via pulse oximetry. Laboratory testing has to cover evaluation of infectious diseases (respiratory viral panel including influenza testing during flu season, Streptococcus pneumoniae, Legionella pneumophila, Mycoplasma pneumoniae, endemic mycoses and opportunistic infections); initial laboratory evaluation (complete blood count with differential, liver transaminases and inflammatory markers, e.g. erythrocyte sedimentation rate and C-reactive protein); urine toxicology testing, with informed consent, including testing for THC; chest radiograph (CXR) (pulmonary infiltrates) and chest computed tomography (CT) (opacities). All these imaging investigations are mandatory for evaluation of severe or worsening diseases, complications such as pneumothorax or pneumomediastinum or other illnesses such as pneumonia or pulmonary embolism. It is also important to see exactly by CT all the details when chest $\mathrm{X}$-ray result does not correlate with clinical findings (one example - bilateral ground glass opacities despite a normal or non-diagnostic CXR) (18). For inpatients, it is important to optimise the management by adding consultation with pulmonary, critical care, medical toxicology, infectious disease, psychology, psychiatry and addiction medicine specialists. Another possibility consists of additional testing with $B A L$ (to rule out alternative diagnoses such as pulmonary infection) or lung biopsy as clinically indicated, in consultation with pulmonary specialists $(16,18)$. Critical care physicians should be consulted to determine optimal management of respiratory failure because $47 \%$ (159/342) of patients were admitted to an intensive care unit and 22\% (74/338) required endotracheal intubation and mechanical ventilation $(16,18)$. The treatment algorithm was also defined (16). Because $8.96 \%$ of the patients were hospitalised, the criteria of accepting patients in hospital must be well known by everyone. Suspected EVALI patients should be admitted if they have decreased $\mathrm{O}_{2}$ saturation $(<95 \%)$ on room air, respiratory distress or comorbidities that compromise pulmonary reserve $(16,18)$. There are two directions to follow up:

- For hospitalising, it is strongly suggested admitting patients with potential lung injury, especially if they have respiratory distress, comorbidities that compromise pulmonary reserve or decreased $(<95 \%) \mathrm{O}_{2}$ saturation (considering in the same time modifying factors such as altitude to guide interpretation).

- For outpatient management of patients with suspected lung injury who have less severe injury, it might be evaluated by specialists on a case-by-case basis (18). Concerning the medical treatment, it is recommended that initiation of corticosteroids and early start of antimicrobial coverage for community-acquired pneumonia should be strongly considered in accordance with established guidelines (18) (valuable also for influenza antivirals). If the patients are not admitted in the hospital, a follow-up within 24-48 $\mathrm{h}$ to assess and manage possible worsening lung injury is necessary. Patients with EVALI can be managed as outpatients if they have oxygen saturation at $95 \%$ or above on room air, no respiratory distress and no comorbid conditions that could impair pulmonary reserve and also reliable access to care and social support systems. They must be instructed to promptly seek medical care if respiratory symptoms worsen. For all the doctors, it is important to consider empiric use of antimicrobials and antivirals $(16,18)$. It was also well defined the follow-up of the post-hospital discharge patients: first visit must be in 1-2 weeks with pulse oximetry testing, spirometry and diffusion capacity testing, and repeated chest radiograph in 1-2 months. Endocrinology consultation is necessary for patients treated with high-dose corticosteroids. The mission of cessation and preventive care services are also important. Here it emphasised to:

- strongly advise patients to discontinue use of e-cigarette, or vaping, products;

- provide education and cessation assistance for patients to aid nicotine addiction and treatment or referral for patients with marijuana-use-disorder;

- stress importance of routine influenza vaccination and

- consider pneumococcal vaccine (18).

What is hard to understand for me is why we arrive to have this new disease? We did not react to the aggressive promotion 
of these products made by the tobacco industry. We did not introduce new extension in our laws in time. Only now (november 2019) Massachusetts became the first state to ban flavoured tobacco and nicotine vaping products, including menthol cigarettes, after Republican Governor Charlie Baker signed into law on Wednesday a bill that is meant to reduce the appeal of the products to young people amid a rash of illnesses and deaths linked to vaping (19). Very late, the associations of doctors also started to react. On 16 November 2019, the Comité Permanent Des Médecins Européens (CPME) board adopted the 'CPME Policy on Novel Tobacco and Nicotine Products' (CPME 2019/074 FINAL) (20). CPME recommendations call on policymakers to:

- recognise that novel tobacco and nicotine products are harmful;

- prohibit health claims for e-cigarettes and heated tobacco products, including claims relating to their effectiveness as smoking cessation aids;

- prohibit use of novel tobacco and nicotine products where smoking is banned;

- prohibit cross-border advertising, promotion and sponsorship of e-cigarettes and heated tobacco products and especially their marketing to children and non-smokers;

- prohibit sale of e-cigarettes and heated tobacco products to minors and to eliminate vending machines for them;

- ban flavourings in electronic nicotine delivery products and heated tobacco products;

- support and encourage independent scientific research regarding the health risks and long-term effects of e-cigarettes and heated tobacco products;

- ensure that the cost of novel tobacco and nicotine products is maintained at a high level similar to the cost of conventional cigarettes;

- harmonise costs of novel tobacco and nicotine products between the European Union (EU) member states;

- establish an EU minimum excise duty rate for e-cigarettes and heated tobacco products;

- continue to try to prevent young people starting smoking conventional cigarettes and novel products and

- continue to try to reduce overall tobacco use by encouraging people to quit and supporting those who are trying to reduce or stop their use of tobacco and nicotinecontaining products.

CPME calls on European doctors to "follow the latest independent research on the health effects of novel tobacco and nicotine products, to inform their patients about the health risks associated with e-cigarettes and heated tobacco products, to encourage their patients to quit smoking and to promote healthy lifestyles, to influence central and local authorities to reduce accessibility to all tobacco and nicotine products, especially by young people and not to recommend novel tobacco or novel nicotine products as means to stop or reduce smoking".

\section{Conclusions}

A new chapter in the pathological findings is opened and generated by the delay of reactions of doctors, authorities and associations of patients. This new disease must change the reactions of doctors in front of a potential EVALI illness. They have to ask patients with flu-like symptoms about their use of e-cigarettes and vaping to strongly consider influenza testing during flu season, to evaluate every suspected EVALI cases with pulse oximetry and chest imaging and to learn outpatient management for stable EVALI with caution use of corticosteroids in patients who are not admitted.

\section{References}

1. Gilbert H. United States Patent Office. 1965. Accessed December 1, 2019. United States Patent Office 3,200,819 Patented Aug. 17, 1965, Smokeless NON-TOBACCO CIGARETTE Herbert A. Gilbert, 278 McKinley Road, Beaver Falls, Pa. Filed Apr. 17, 1963, Ser. No. 273,624 10 Claims. (C. 128-208).

2. Health Effects of Cigarette Smoking. (2014, February 6). Centers for Disease Control and Prevention. [Accessed 1st December 2019].

3. Grana R, Benowitz N, Glantz SA. Background paper on E-cigarettes (electronic nicotine delivery systems). Center for Tobacco Control Research and Education, University of California, San Francisco, a WHO Collaborating Center on Tobacco Control. Prepared for World Health Organization Tobacco Free Initiative. December 2013. [Accessed 1st December 2019].

4. Elia J. Two Vaping Advisories Released by CDC- Medical News | Physician's First Watch November 20, 2019.

5. Korin Miller. What Is EVALI? Symptoms of Vaping-Related Lung Illness May Feel Like the Flu- Medical Definition of EVALI, Written by Doctors - MedicineNet. Available from: https://www. medicinenet.com, Oct 16, 2019.

6. Navon L, Jones CM, Ghinai I, King BA, Briss PA, Hacker KA, et al. Risk factors for E-Cigarette, or Vaping, Product Use-Associated Lung Injury (EVALI) among adults who use E-cigarette, or vaping, products - Illinois, July-October 2019. MMWR Morbidity and Mortality Weekly Report. 2019;68(45): 1034-1039.

7. Ritchel M. New York State suspects vitamin E may have played a role in vaping illnesses. New York Times. September 5, 2019. Available from: https://www.nytimes.com/2019/11/08/health/ vaping-illness-cdc.

8. Ritchel M, Grady D. What you need to know about vapingrelated lung illness. New York Times. September 11, 2019. 
Available from: https://www.nytimes.com/2019/09/07/health/ vaping-lung-illness.html?smid=nytcore-ios-share.

9. Massey JB, She HS, Pownall HJ. Interaction of vitamin E with saturated phospholipid bilayers. Biochemical and Biophysical Research Communication. 1982;106: 842-847.

10. Casals $C$, Cañadas $O$. Role of lipid ordered/disordered phase coexistence in pulmonary surfactant function. Biochimica et Biophysica Acta. 2012;1818: 2550-2562.

11. Downs D. Amid Vape Pen Lung Disease Deaths: What Exactly is Vitamin E Oil? Seattle, WA: Leafly; 2019. Available from: https:// www.leafly.com/news/health/vape-pen-lung-disease-vitamin-eoil-explained [Google Scholar].

12. Blount BC, Karwowski MP, Morel-Espinosa M, Rees J, Sosnoff C, Cowan E, et al. Evaluation of Bronchoalveolar Lavage Fluid from Patients in an Outbreak of E-cigarette, or Vaping, Product Use-Associated Lung Injury - 10 States, August-October 2019. MMWR Morbidity and Mortality Weekly Report. 2019;68(45): 1040-1041.

13. CDC. Outbreak of Lung Injury Associated with the Use of E-cigarette, or Vaping, Products. Atlanta, GA: US Department of Health and Human Services, CDC; 2019. Availble from: https:// www.cdc.gov/tobacco/basic_information/e-cigarettes/severelung-disease.html\#what-cdc-recommends.

14. Moritz ED, Zapata LB, Lekiachvili A, Glidden E, et al.; Lung Injury Response Epidemiology/Surveillance Group; Lung Injury Response Epidemiology/Surveillance Task Force. Update: characteristics of patients in a national outbreak of e-cigarette, or vaping, product use-associated lung injuries_ United States, October 2019. MMWR Morbidity and Mortality Weekly Report 2019;68: 985-959.
15. Chatman-Stephens K., Roguski K, Jang Y, Cho P, Jatlaoui TC, Kabbani S, et al. Characteristics of hospitalised and non hospitalised patients in a Nationwide outbreak of E-cigarette or Vaping, Product use- associated lung injuries - United States, November 2019. MMWR Morbidity and Mortality Weekly Report. 2019;68(46): 1076-1080.

16. Jatlaoui TC, Wiltz JL, Kabbani S, Siegel DA, Koppaka R, Montandon M, et al. Update: Interim Guidance for Health Care Providers for Managing Patients with Suspected E-cigarette, or Vaping, Product Use-Associated Lung Injury — United States, November 2019-US Department of Health and Human Services/Centers for Disease Control and Prevention. MMWR. 2019;68(46): 1081-1086.

17. Layden JE, Ghinai I, Pray I, Kimball A, Layer M, Tenforde M, et al. Pulmonary illness related to e-cigarette use in Illinois and Wisconsin-preliminary report. The New England Journal of Medicine. 2019. Epub September 6, 2019. Available from: doi:10.1056/NEJMoa1911614.

18. Siegel DA, Jatlaoui TC, Koumans EH, Kiernan EA, et al.; Lung Injury Response Clinical Working Group; Lung Injury Response Epidemiology/Surveillance Group. Update: interim guidance for health care providers evaluating and caring for patients with suspected e-cigarette, or vaping, product use associated lung injury-United States, October 2019. MMWR Morbidity and Mortality Weekly Report. 2019;68: 919-927.

19. Marcelo Ph. No more menthol cigarettes: New ban on tobacco, vape flavours- November 28, 2019 App. News.

20. Comite permanent des medicins europeens (CPME) 2019/074 FINAL. 